http://jmscr.igmpublication.org/home/ ISSN (e)-2347-176x ISSN (p) 2455-0450 crossref DOI: https://dx.doi.org/10.18535/jmscr/v8i9.07

Journal Of Medical Science And Clinical Research

\title{
Comparative Study between Tamsulosin and Silodosin as a Medical Expulsive Therapy for Lower Ureteral Stones
}

Authors

Dr Md. Shahidul Islam ${ }^{*}$, Dr Md. Mostafiger Rahman ${ }^{2}$, Dr Wahida Akhtar Chowdhury $^{3}$, Dr Md. Mahabubul Islam ${ }^{4}$, Dr Mst. Rawshon Ara Begum ${ }^{5}$

${ }^{1}$ Associate Professor, Department of Urology, Rangpur Medical College, Rangpur, Bangladesh

${ }^{2}$ Assistant Professor, Department of Urology, Prime Medical College, Rangpur, Bangladesh

${ }^{3}$ Anesthesiologist, Department of Anesthesiology, Rangpur Medical College Hospital, Rangpur, Bangladesh

${ }^{4}$ Assistant Professor, Department of Community Medicine, Rangpur Medical College, Rangpur, Bangladesh

${ }^{5}$ Assistant Professor, Department of Obstetrics and Gynaecology, Rangpur Medical College, Rangpur,

Bangladesh

*Corresponding Author

Dr Md. Shahidul Islam

\begin{abstract}
Objectives: To compare the efficacy of tamsulosin and silodosin as medical expulsive therapy (MET) for lower ureteric stones.

Materials and Methods: A prospective randomized study was conducted at outpatient department of Urology, Rangpur Medical College Hospital, Rangpur, Bangladesh during January 2017 and May 2019. A total of 220 patients with single unilateral lower ureteric stones $10 \mathrm{~mm}$ or less were included in this study. Cases were selected by inclusion and exclusion criteria and randomly allocated in two groups. Tamsulosin group (110 patients) and silodosin group (110 patients) were given tamsulosin 0.4mg and silodosin $8 \mathrm{mg}$ daily at bed time respectively. The patients were prescribed diclofenac $(50 \mathrm{mg})$ on demand for pain relief and were followed-up on weekly for 4 weeks by X-ray and ultrasonography of kidney, ureter and urinary bladder region. The expulsion rate, expulsion time, and analgesic requirements were also recorded. Data were analyzed and compared by statistical tests.

Results: According to our results, no statistically significant difference was found in terms of age, gender and stone size distribution between two groups. The stone expulsion rate was significantly higher in the silodosin group compared with the tamsulosin group, at $85.46 \%$ and $70.91 \%$, respectively $(p=0.009)$. The stone expulsion time was also significantly lower in silodosin against tamsulosin groups as it was $13.12 \pm 5.65$ days vs. $16.6 \pm 5.2$ days respectively $(p=0.0001)$. The variation between analgesic doses required by patients in both groups were found statistically not significant $(p=0.158)$. Overall, adverse effects were similar in both groups.

Conclusions: Silodosin is more effective than tamsulosin as medical expulsive therapy for lower ureteric stones.

Keywords: Tamsulosin,Silodosin, Ureter, Stone.
\end{abstract}




\section{Introduction}

Urolithiasis and its management have become a global growing concern posing both a clinical and economic burden for healthcare systems ${ }^{[1]}$. Urinary stone disease is one of the most common reasons for patients visiting a urology practice, affecting about $5 \%$ to $10 \%$ of the population and about $70 \%$ of them are found in the lower third of the ureter at presentation ${ }^{[2,3]}$. The transport of stones from the kidney into the bladder and their movement through the ureter is accompanied by three basic factors; spasm of smooth muscles, submucosaledema and pain ${ }^{[4]}$. In the transport of stones, the greatest obstacle is usually the terminal part of the ureters, mainly in the intramural 'detrusor tunnel'. Stone location, size, number, ureteric spasm, mucosal edema or inflammation, and ureteric anatomy are the factors affecting passage of ureteric stones ${ }^{[5]}$.

Guidelines of American Urologic Association and European Association of Urology have recommended that patients with ureteral stones less than $10 \mathrm{~mm}$ be followed for stone passage and receive an appropriate medical therapy ${ }^{[6,7]}$. Ureteral calculi of any size are often associated with renal obstruction, and care must be taken to prevent irreversible damage to the kidney whether choosing expectant or active management. Multiple management options for ureteric stones are present, such as conservative, medical expulsive therapy (MET), extracorporeal shockwave lithotripsy (ESWL), ureteroscopy and open surgical procedures. Improvements in minimally invasive procedures in the last few decades have considerably changed the treatment of ureteral stones, but such procedures are not free of risks and are costly as well.

A conservative approach through medical expulsive therapy (MET) has now become an established treatment modality that employs various drugs acting on the ureter by different mechanisms. According to European Association of Urology Guidelines, alpha-blockers or nifedipine are recommended for MET (grade of recommendation $\mathrm{A})^{[7]}$. In 1970, Malin et al. demonstrated the presence of alpha and beta adrenergic receptors (AR) in the human ureter ${ }^{[8]}$. Alpha1 are the most abundant AR subtypes at the level of ureteric smooth muscle cells ${ }^{[9]}$. Itoh et al. demonstrated that three types of alphal AR areexpressed in the human ureter (alpha1A, alpha1B and alpha1D) ${ }^{[10]}$. The blocking of these receptors subsequently induces selective relaxation of the ureteric smooth muscle, which will result in ureteric lumen dilatation facilitating antegrade stone propagation ${ }^{[11,12,13,14]}$.

Tamsulosin, a selective alpha blocker with equal affinity for both a-1A and a-1D receptors, has a proven role in MET in increasing the stone expulsion rate and decreasing expulsion time ${ }^{[15,16]}$. Recently, it has been suggested that silodosin, which is higher alpha 1a selective and nowadays increasingly used, is more potent in MET compared to tamsulosin ${ }^{[17,18]}$. Silodosin is a highly selective alpha1A adrenoceptor blocker that has 162 times more affinity for alpha1A than $\mathrm{B}$, so it has less undesired effects on the regulation of blood pressure and it was effective as medical expulsive therapy (MET) for lower ureteric stone ${ }^{[19]}$. The objective of the present study was to compare the efficacy of tamsulosin and silodosin as medical expulsive therapy (MET) for lower ureteric stone.

\section{Materials and Methods}

A prospective randomized study was conducted in the outpatient department of urology of Rangpur Medical College Hospital, Rangpur, Bangladesh betweenJanuary2017 and May 2019. A total of 220 patients were included in this study. The Inclusion criteria were single, unilateral, symptomatic, radiopaque stone of $10 \mathrm{~mm}$ or smaller in the largest dimension in lower ureter. A lower ureteric stone was located in pelvic cavity from below the lower border of the sacroiliac joint to ureteric orifice. The exclusion criteria were included a single kidney, multiple ureteric stones, bilateral ureteric stones, renal impairment, UTI, high-grade hydronephrosis (Grades 3 and 4 according to Society of Fetal Ultrasound, SFU), 
previous therapies for the stone, previous endoscopic or surgical interventions, concomitant treatment with calcium antagonists, corticosteroids or nitrates; pregnant or lactating mothers, diabetic patients and those who refused to enroll in the study.

All patients were was assessed by physical examination, complete blood count, serum creatinine level, urine $\mathrm{R} / \mathrm{M} / \mathrm{E} \&$ culture, plain abdominal radiograph of the kidneys, ureters and bladder (KUB), ultrasonography of the KUB region as needed. Every patient provided informed written consent after receiving information about the nature of the study, time to study end, adverse effects, and the possibility of intervention if needed.

The patients were randomly divided into two groups; Tamsulosin group (110patients) received a single dose of tamsulosin $(0.4 \mathrm{mg})$ and Silodosin group (110 patients) received a single dose of silodosin $(8 \mathrm{mg})$ daily at bed time. In all two groups, drugs were continued until stone expulsion or for a maximum of 4 weeks. Patients were instructed to take plenty of fluids, tablet diclofenac $50 \mathrm{mg}$ per orally during episodes of pain, and filter their urine by using a standard mesh net to detect stone expulsion.

Follow-up was performed every week for 4 week by asking the patient about stone passage, time of stone passage, attacks of renal colic \& analgesic requirements and symptoms related to side-effects of the drugs. The patients were followed-up until stone passage was confirmed by plain X-ray and ultrasonography of KUBor at the end of the study period (4 weeks) and surgical intervention. Complete stone expulsion was defined as complete passage of stone as evidenced by patient and was confirmed by X-ray or USG of KUB within 4 week or earlier. Stone expulsion failure was considered if the patient failed to pass the stone at the end of 4 weeks or endoscopic intervention. The stone expulsion rate, expulsion time, doses of analgesic requirements were also recorded. For data analysis p-value $<0.05$ was considered significant.

\section{Results}

Mean ages of the patients in the tamsulosin and silodosin groups were $35.5 \pm 11.08$ and $34.8 \pm$ 10.8 years respectively $(\mathrm{p}=0.6356)$. The mean stone size was $5.94 \pm 1.18 \mathrm{~mm}$ for tamsulosin and $5.95 \pm 1.07 \mathrm{~mm}$ for silodosin group $(\mathrm{p}=0.9476)$. There was no side predominance in any of the groups. There was no statistical significant difference in age, gender and stone size distribution between the two groups. A stone expulsion rate of $70.91 \%$ (78 out of 110 patients) in tamsulosin group and $85.46 \%$ (94 out of 110 patients) was observed for silodosin group. Tamsulosin group showed a statistically significant advantage in terms of the stone expulsion rate $(\mathrm{p}=0.009)$. According to stone expulsion time in tamsulosin group, mean expulsion time were16.6 \pm 5.2days whereas in silodosin group had mean expulsion time of 13.12 \pm 5.65 days $(\mathrm{p}=0.0001)$. Overal doses of analgesic (diclofenac) required in tamsulosin group was ranged from 50-500 $\mathrm{mg}$ whereas in silodosin group was observed to be $50-450 \mathrm{mg}$. The variation between doses required by patients in both groups were found to statistically not significant ( $\mathrm{p}=0.158)$. Drug-related adverse effects such as headache $(10.90 \%$ Vs $14.54 \%)$, postural hypotension $(05.45 \%$ Vs $03.63 \%)$ were more in tamsulosin group patients than silodosin groups but this was not statistically significant ( $p>$ 0.05).In males, retrograde ejaculation was reported in $07.27 \%$ in tamsulosin group and $04.54 \%$ in silodosin groups but it was again statistically non-significant $(\mathrm{p}=0.3910)$.

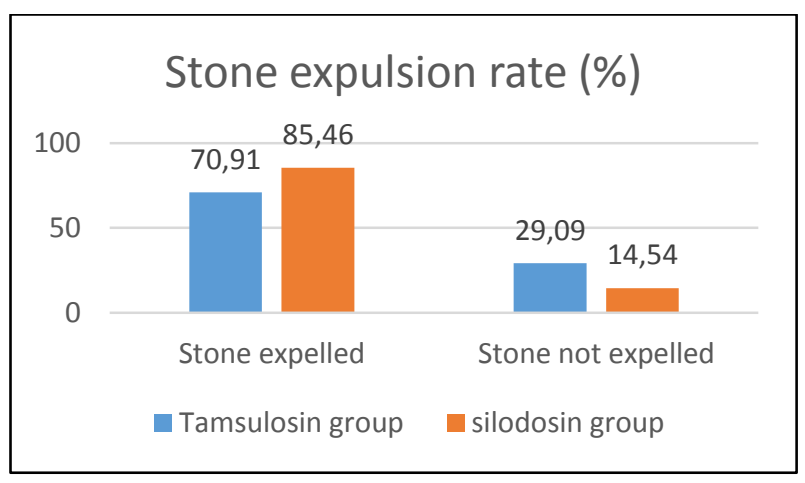

Fig 1: Comparison of stone expulsion rate in between two groups. 
Table 1. Comparison of variables in between two groups

\begin{tabular}{|c|c|c|c|}
\hline Variables & $\begin{array}{c}\text { Tamsulosi } \\
\text { n Group } \\
\text { n=110 }\end{array}$ & $\begin{array}{c}\text { Silodosin } \\
\text { Group } n=110\end{array}$ & $p$ value \\
\hline \multicolumn{4}{|l|}{$\operatorname{Age}(y)$} \\
\hline Mean \pm SD & $35.5 \pm 11.08$ & $34.8 \pm 10.8$ & 0.6356 \\
\hline \multicolumn{4}{|l|}{ Gender, n (\%) } \\
\hline Male & $72(65.46)$ & $76(69.09)$ & \multirow[b]{2}{*}{0.5654} \\
\hline Female & $38(34.54)$ & $34(30.91)$ & \\
\hline \multicolumn{4}{|l|}{ Laterality, n (\%) } \\
\hline Left Ureter & $50(45.46)$ & $45(40.90)$ & \multirow[b]{2}{*}{0.4961} \\
\hline Right ureter & $60(54.54)$ & $65(59.09)$ & \\
\hline \multicolumn{4}{|l|}{ Stone size $(\mathrm{mm})$} \\
\hline Mean \pm SD & $5.94 \pm 1.18$ & $5.95 \pm 1.07$ & 0.9476 \\
\hline \multicolumn{4}{|l|}{$\begin{array}{l}\text { Stone expulsion } \\
\text { rate, } n(\%)\end{array}$} \\
\hline Yes & $78(70.91)$ & $94(85.46)$ & \multirow[b]{2}{*}{0.0090} \\
\hline No & $32(29.09)$ & $16(14.54)$ & \\
\hline \multicolumn{4}{|l|}{$\begin{array}{l}\text { Stone expulsion } \\
\text { time, }(\text { d })\end{array}$} \\
\hline Mean \pm SD & $16.6 \pm 5.2$ & $13.12 \pm 5.65$ & 0.0001 \\
\hline \multicolumn{4}{|l|}{$\begin{array}{l}\text { Analgesic } \\
\text { requirements, } \\
\text { (doses-mg) }\end{array}$} \\
\hline Range & $50-500$ & $50-450$ & 0.1580 \\
\hline \multicolumn{4}{|l|}{$\begin{array}{l}\text { Adverse effects, } n \\
(\%)\end{array}$} \\
\hline $\begin{array}{l}\text { Postural } \\
\text { hypotension }\end{array}$ & $6(05.45)$ & $4(03.63)$ & 0.5174 \\
\hline $\begin{array}{l}\text { Retrograde } \\
\text { ejaculation in male }\end{array}$ & $8(07.27)$ & $5(04.54)$ & 0.3910 \\
\hline Headache & $12(10.90)$ & $16(14.54)$ & 0.4184 \\
\hline
\end{tabular}

\section{Discussion}

According to the European Association of Urology (EAU) and the American Urologic Association (AUA) joint Guideline for the Management of Ureteral Calculi, patients with a newly diagnosed ureteral stone $<10 \mathrm{~mm}$ and whose symptoms are controlled, observation with periodic evaluation is an option for initial treatment. ${ }^{6}$ Such patients may be offered an appropriate medical expulsive therapy to facilitate stone passage during the observation period. Spontaneous stone expulsion can occur in up to $50 \%$ of cases, nevertheless, many complications suchas ureteric colic, UTI, and hydronephrosis may occur. Use of MET for lower ureteric calculi has helped to reduce pain, complications and increase the rate of stone clearance ${ }^{[20]}$. Different modalities of medical expulsive therapy have been evaluated, including alpha-blockers, calcium channel blockers, corticosteroids and combinations of aforementioned. Most experience has been achieved with alpha-blockers ${ }^{[11,13]}$. The majority of ureteral calculi can pass spontaneously and intervention is usually not required. It is estimated that $95 \%$ of stones up to $4 \mathrm{~mm}$ pass spontaneously within 40 days ${ }^{[6]}$. A meta- analysis by the AUA guidelines panel determined that ureteral stones with a diameter of $<5 \mathrm{~mm}$ will pass in up to $98 \%$ of cases. MET is usually established as an initial treatment plan of lower ureteric calculi of size 5-10 mm, as they are less likely to pass spontaneously ${ }^{[21]}$. Several studies stated that the rate of ureteric stone expulsion by watchful waiting is $25-54 \%$ with a mean expulsion time of more than 10 days accompanied by high analgesic requirement even for stones less than $5 \mathrm{~mm}$, and so MET was instituted to improve the expulsion rate, reduce the expulsion time, and minimize analgesic requirement ${ }^{[21,22]}$.

In 2007, the collaborative European Association of Urology (EAU)/American Urological Association Urolithiasis Working Groups published a systematic review that demonstrated a beneficial effect of a-blockers on the spontaneous stone passage rate of distal ureteral stones ${ }^{[6]}$. The term medical expulsive therapy (MET) was born, and the use of a-blockers was recommended as an adjunct for uncomplicated distal ureteral stones $<10 \mathrm{~mm}^{[7]}$. A meta-analysis of MET was also performed which demonstrated that alpha blockers facilitate stone passage and the majority of stones pass spontaneously within four to six weeks. Irreversible renal damage does not tend to occur with an incomplete obstruction for the first 4 weeks in the absence of an aggravating factor, such as urinary tract infection ${ }^{[23]}$. Therefore, a logical approach in the absence of aggravating factors appears provision of MET only after the passage of 4 weeks. Cervenàkov et al demonstrated that standard treatment was supplemented by the administration of the alpha-1 blocker, helped to accelerate the passing of minor calculi from the terminal parts of the ureters of $80.4 \%$ of patients ${ }^{[24]}$. Selective alpha-blockers have a crucial impact in spontaneous painless 
elimination of the stones smaller than $8 \mathrm{~mm}$ located in the uretero-bladder junction ${ }^{[25]}$.

In our present study, the stone clearance rate was significantly higher in the silodosin group compared with the tamsulosin group, at $85.46 \%$ and $70.91 \%$, respectively $(\mathrm{P}=0.009)$.Our results are in agreement with those of Gupta et al. who reported stone clearance rates of $82 \%$ and $58 \%$ for their silodosin and tamsulosin groups respectively ${ }^{[26]}$. Kumar et al. also reported stone clearance rates of $83.3 \%$ and $64.4 \%$ for their silodosin and tamsulosin groups, respectively ${ }^{[27]}$. Elgalaly et al. also reported the stone clearance rate was significantly different between the groups, at $83 \%$ in solidosin group vs $57 \%$ in tamsulosin group $(\mathrm{p}=0.007)^{[17]}$. However, Imperatore et al. reported a non-significant difference of stone clearance rates between silodosin $(88 \%)$ and tamsulosin $(84 \%)^{[28]}$. In present study, the stone expulsion time was significantly shorter in the silodosin group vs the tamsulosin group, at $13.12 \pm 5.65 \mathrm{vs} 16.6 \pm 5.2$ days, respectively $(p=0.0001)$.Gupta et al. reported significantly shorter stone expulsion times in silodosin group vs the tamsulosin group, at 12.5 (3.5) vs 19.5 (7.5) days, respectively ${ }^{[26]}$. Some study also shows dissimilar results in terms of stone expulsion times ${ }^{[17,27,28]}$.

Colicky pain in ureteral stone occurs due to an increase in intraureteral pressure above the site of ureteral obstruction $^{[27]}$. The alpha adreno- ceptor blockers may alleviate the ureteric colic by blocking $\mathrm{C}$ fibers that mediates pain and decreases the analgesic requirements by decreasing the stone expulsion time ${ }^{[17]}$. In this study, the analgesic requirements are comparable in both silodosin and tamsulosin groups with no significant difference ( $p=0.15$ ).Meanwhile, Kumar et al. reported significant less analgesic requirement in the silodosin group versus the tamsulosin group, as it was $195 \pm 10.2$ and $220 \pm 10.8$ respectively $(\mathrm{p}=0.001)^{[27]}$. However, several studies comparing tamsulosin and silodosin suggested that statistically higher stone expulsion rates and mean shorter stone expulsion times in patients receiving $\operatorname{silodosin}^{[17,26,27,28]}$. This may be explained by the selective alpha 1A adrenoceptive antagonistic action of silodosin when compared to alpha $1 \mathrm{~A}$ antagonistic action of tamsulosin suggesting better clinical usefulness of silodosinand $\alpha$-receptors are more abundant in the distal ureter. In addition, when the drugs were compared in terms of common side effects (headache and postural hypotension retrograde ejaculation), no significant difference was found, supporting previous studies $[27,28,29,30]$

A limitation of the present study is that CT KUB was not done to assess the ureteric stone because of financial constraint. Since this is a single centre study, a multi centre study at a larger scale is required.

\section{Conclusions}

Silodosin is found to be more effective than tamsulosin as medical expulsive therapy for treatment of lower ureteric stones.

\section{Conflicts of Interest}

The authors declare no conflicts of interest regarding the publication of this paper.

\section{References}

1. Turney BW, Reynard JM, Noble JG, Keoghane SR. Trends in urological stone disease. BJU Int 2012;109:1082-1087.

2. Ramello A, Vitale C, Marangella M. Epidemiology of nephrolithiasis. Journal of Nephrology 2000;13Suppl 3: S45-50. [MEDLINE: 11132032]

3. Pearle MS and LotanY ;Urinary lithiasis: etiology, epidemiology and pathogenesis. In: Campbell-Walsh Urology. Wein AJ, Kavoussi LR, Novick AC, Partin AW, Peters CA, editors. 10th ed. Philadelphia: Saunders Elsevier, 2012: pp: 1257-1286.

4. R Ranjan, P Kumari, M Mundu, R Baxla. The role of tamsulosin and deflazacort in the expulsion of up to 6 in mid and lower ureteric calculi . The Internet Journal of Urology. 2013: 11(1). 
5. Michael E.L, Michael N.F., Glenn M.P. Evaluation and medical management of urinary urolithiasis.In: Campbell-Walsh Urology. Wein AJ, Kavoussi LR, Partin AW, Peters CA., editors. 11th ed. Philadelphia: Elsevier; 2016. pp 12001234

6. Preminger GM, Tiselius H-G, Assimos DG, et al. 2007 Guideline for the management of ureteral calculi. J Urol. 2007; 178:2418-2434.

7. Türk C, Petrík A, Sarica K, et al. EAU guidelines on diagnosis and conservative management of urolithiasis. Eur Urol. 2016;69:468-474.

8. Malin JM Jr, Deane RF, Boyarsky S. Characterisation of adrenergic receptors in human ureter.Br J Urol. 1970; 42:171-4.

9. Küpeli B, Irkilata L, Gürocak $\mathrm{S}$, et al. Does tamsulosin enhance lower ureteral stone clearance with or without shock wavelithotripsy? Urology. 2004; 64:11115.

10. Itoh Y, Kojima $\mathrm{Y}$, Yasui $\mathrm{T}$, et al. Examination of alpha 1 adrenoceptor subtypes in the human ureter. Int J Urol. 2007; 14:749-53.

11. Yilmaz E, Batislam E, Basar MM, et al. The comparison and efficacy of 3 different alpha1-adrenergic blockers for distal ureteral stones. J Urol. 2005; 173:2010-2.

12. De Sio M, Autorino R, Di Lorenzo G, et al. Medical expulsive treatment of distalureteral stones using tamsulosin: a singlecenter experience. J Endourol. 2006; 20:12-6.

13. Singh A, Alter HJ, Littlepage A. A systematic review of medical therapy to facilitate passage of ureteral calculi. Ann Emerg Med 2007; 50:552-63.

14. Yuksel M, Yilmaz S, Tokgoz H, et al. Efficacy of silodosin in the treatment of distal ureteral stones 4 to $10 \mathrm{~mm}$ in diameter. Int J ClinExp Med. 2015;8(10):19086-19092.
15. Ahmad H, Azim W, Akmal M, Murtaza B, Mahmood A, Nadim A, et al. Medical expulsive treatment of distal ureteral stone using tamsulosin. J Ayub Med Coll Abbottabad. 2015;27 (1):4850.

16. Campschroer T, Zhu X, Vernooij RWM, Lock MTWT. Alpha- blockers as medical expulsive therapy for ureteral stones. Cochrane Database of Systematic Reviews 2018, Issue 4. Art. No.: CD008509. DOI: 10.1002/14651858.CD008509.pub3.

17. Gharib T, Mohey A, Fathi A, Alhefnawy M, Alazaby H, Eldakhakhny A. Comparative Study between Silodosin and Tamsulosin in Expectant Therapy of Distal Ureteral Stones. UrolInt2018;101:161-166 https://doi.org/10.1159/000490623.

18. Elgalaly H, Sakr A, Fawzi A, et al. Silodosin vs tamsulosin in the management of distal ureteric stones: A prospective randomised study. Arab J Urol. 2016;14(1):12-17. doi:10.1016/j.aju.2015.11.004

19. Tsuzaka Y, Matsushima H, Kaneko T, et al: Naftopidilvs silodosin in medical expulsive therapy for ureteral stones: a randomized controlled study in Japanese male patients. Int J Urol 2011; 18: 792 795.

20. Dellabella M, Milanese G, Muzzonigro G. Randomized trial of the efficacy of tamsulosin, nifedipine and phloroglucinol in medical expulsive therapy for distal ureteral calculi. J Urol2005;174:167-72

21. Bensalah K, Pearle M, Lotan Y: Cost effectiveness of medical expulsive therapy using alpha blockers for the treatment distal ureteral stones. EurUrol 2008; 53: 411-418.

22. Wolf JS Jr: Treatment selection and outcomes: ureteral calculi. UrolClin N Am 2007; 34: 421-430

23. Tiselius HG, Ackermann D, Alken P, et al. Guidelines on urolithiasis. European Association of Urology [website]. 
https://uroweb.org/wp-

content/uploads/EAU-Guidelines-

Urolithiasis-2008.pdf

24. Cervenakov I, Fillo J, Mardaik J, Kopency M, Smilrala J, Lepies. Speedy elimination of urolithiasis in lower part of ureters with alpha1 blockers tamsulosin. Int $\mathrm{J}$ Urol Nephrol. 2002; 34:25-9.

25. Pricop C, Novac C, Negru D, Iiie C, Pricop A, Tanase A. Can selective alpha blockers help the spontaneous passage of the stones located in the uretero bladder junction? Rev Med ChirSoc Med Nat. 2004; 108:128-33.

26. Gupta S, Lodh B, Singh AK, Somarendra K, Meitei KS, Singh SR. Comparing the efficacy of tamsulosin and silodosin in the medical expulsion therapy for ureteral calculi. J ClinDiagn Res 2013;7:1672-4.

27. Kumar S, Jayant K, Agrawal MM, Singh SK, Agrwal S, Parmar KM. Role of tamsulosin, tadalafil, and silodosin as the medical expulsive therapy in lower ureteric stone: a randomized trial (a pilot study). Urology 2015;85:59-63

28. Imperatore V, Fusco F, Creta M, Di Meo $\mathrm{S}$, Buonopane R, Longo N, et al. Medical expulsive therapy for distal ureteric stones: tamsulosin versus silodosin. Arch ItalUrolAndrol2014;86:103-7.

29. Dell'Atti L: Silodosin versus tamsulosin as medical expulsive therapy for distal ureteral stones: a prospective randomized study. Urologia. 2014, 82:54-7. 10.5301/uro.5000083

30. Gharib T, Mohey A, Fathi A, Alhefnawy M, Alazaby H, Eldakhakhny A: Comparative Study between Silodosin and Tamsulosin in Expectant Therapy of Distal Ureteral Stones. UrolInt2018;101:161-166. doi: 10.1159/000490623. 